\title{
An evidence-based review on religiosity in psychiatry
}

\begin{abstract}
Objective: Religiosity and/or spirituality (R/S) has a deep impact on human psyche This review describes the evidence on $\mathrm{R} / \mathrm{S}$ on mental health. $72.1 \%$ if the studies find a positive relationship between $\mathrm{R} / \mathrm{S}$ and better mental health, $18.6 \%$ find mixed (positive and negative) results, and $4.7 \%$ reported a negative association. All studies on dementia suicide and stress-related disorders found a positive association, as well as $79 \%$ and $67 \%$ of the papers on depression and substance abuse, respectively. There is growing evidence today that $\mathrm{R} / \mathrm{S}$ is correlated with better mental health in the areas of depression, substance abuse, and suicide; insufficient evidence in neurosis and dementia; poor evidence in bipolar disorder and schizophrenia, and no evidence in many other mental disorders.
\end{abstract}

Volume 7 Issue 2 - 2017

\author{
Raphael M Bonelli \\ Associate Professor of Psychiatry, Sigmund Freud University, \\ Austria \\ Correspondence: Raphael M Bonelli,Associate Professor of \\ Psychiatry, Sigmund Freud University Vienna, Austria, \\ Email raphael.bonelli@sfu.ac.at
}

Received: December 02, 2016 | Published: June 29, 2017

Keywords: religiosity, spirituality, psychiatry, depression, addiction, suicide

\section{Introduction}

Religious and spiritual (R/S) dimensions of mental health have been poorly studied in psychiatry in the last 150 years. In the late 19th century, Jean Charcot and Sigmund Freud began to associate religion with hysteria and neurosis. This began a deep divide that would separate religion from mental health care for the next century. ${ }^{1}$ It was Larson and colleagues in 1986, who conducted the first systematic review of quantitative research on $\mathrm{R} / \mathrm{S}$ in psychiatry, focusing on religious variables found in four psychiatric journals between 1978 and 1982. They reported that only $2.5 \%$ of psychiatric articles reviewed included a religious variable. The religious variable examined was often a single static measure of religious affiliation rather than multiple dynamic measures of religious involvement. ${ }^{2}$ Six years later, the same group assessed all measures of religious commitment reported in research studies published in the American Journal of Psychiatry and Archives of General Psychiatry in 1978 through 1989, finding 139 $\mathrm{R} / \mathrm{S}$ measures examined in 35 studies. For the majority of measures assessed, the studies reported a positive relationship between religious involvement and mental health, finding in $72 \%$ a positive correlation, in $16 \%$ a negative correlation, and in $12 \%$ no correlation. ${ }^{3}$ For many years, the work of Larson and colleagues served as a state-of-theart review of associations between religion and mental health. Since then, however, research on the topic has increased dramatically across health disciplines, but has not been analyzed in a systematic way, at least not within psychiatry and neurology.

Due to the large number of reports available, reviews on the topic are often biased by the author's selection of papers. Our aim was to conduct a systematic evidence-based review (EBR) of research on $\mathrm{R} / \mathrm{S}$ and mental disorders between 1990 and 2010, using simple but rigorous selection criteriarating the quality of each study's design and methods, and summarizing the findings.

\section{Methods}

The literature was searched using the electronic database of Pubmed (1990 - December 2010). The search terms used were "religio*" (i.e. religion, religiosity, religiousness, and similar expressions) or "spiritu*" (i.e. spiritual, spirituality, and similar expressions), searching only the title of the article. A total of 5,200 publications were found. To identify the highest quality papers, we selected publications in psychiatric journals ranked in the top $25 \%$ by the ISI citation index 2010, i.e. the top 32 journals out of 126 listed, all with an impact factor of 3.6 or higher. Using this procedure, we identified 108 papers of which 66 were reports of original data-based quantitative research. Interestingly, 13 out of these 32 top journals $(40.6 \%)$ had published no R/S research during that 20 year period (at least none that listed R/S in the title). Fourteen of the 66 papers were excluded because they focused on non-psychiatric diseases (i.e. hypertension, myocardial infarct, epilepsy). The same procedure was performed in the top neurological journals that examined on psychiatric diseases (defines by the WHO ICD-10 group F). Of the 185 neurological journals listed in the ISI citation index, 41 fell into this category. In those journals we located 15 additional papers, of which two reported original research on disorders in ICD-10 group $\mathrm{F}$ and both were included in our review., ${ }^{4,5}$ Twenty-nine of the 41 neurology journals $(69.0 \%)$ had no articles on $\mathrm{R} / \mathrm{S}$ research between 1990 and 2010.

The remaining 54 papers were reviewed by both authors independently. After examining the studies, the authors agreed to exclude six more papers because they did not focus on a specific psychiatric disorder, but rather on well-being, ${ }^{6}$ coping, ${ }^{7-9}$ spiritual healing, ${ }^{10}$ or the serotonin system. ${ }^{11}$ Two papers on schizophrenia did not examine the association between $\mathrm{R} / \mathrm{S}$ parameters and schizophrenia, so they were excluded as well..$^{12,13}$ One more paper was excluded because it turned out to be a case report, ${ }^{14}$ and the studies by Reynolds et al., ${ }^{15}$ and Fallon et al., ${ }^{16}$ were excluded because they did not statistically examine the R/S-mental health relationship. The remaining 43 studies were then discussed and rated for the quality of their design, measures, and statistical methods.

\section{Assessing quality of methods}

The quality of each study was rated by both authors between 1 (lowest quality and 10 (excellent quality) according to the following eight criteria: study design (clinical trial, prospective cohort, cross-sectional, etc.), sampling method (random, systematic, or convenience), number of R/S measures, quality of $\mathrm{R} / \mathrm{S}$ measures, quality of mental health outcome measure, contamination between outcome and R/S measures, inclusion of control variables, and statistical method, based on a scheme adapted from Cooper. ${ }^{17}$ The Pearson correlation between the two ratings was 0.76 , although the authors had discussed a number of the studies prior to rating them. Disagreements were resolved and the ratings presented here 
represent a consensus of the two authors. The mean value of quality score between studies reporting positive relationships between R/S and mental health outcomes vs. non-postitive findings did not differ significantly (7.06 vs 7.08 ). The quality of the design/methods and quality of the statistics were arrived at by consensus, and were rated using five levels: poor, fair, good, very good, and excellent.

Finally, the study findings were placed into seven categories: NA: no association with mental health outcome; P: at least one significant positive association and no significant negative associations; $(\mathrm{P})$ : positive association, but significance level borderline $(0.05<\mathrm{p}<0.10)$; NG: at least one significant negative association with better mental health and no significant positive ones; (NG): negative association, but significance borderline $(0.05<\mathrm{p}<0.10)$; and $\mathrm{M}$ : mixed (both significant positive and significant negative associations with mental health depending on $\mathrm{R} / \mathrm{S}$ measure).

\section{Results}

The results are summarized in Table 1, presented in the order of ICD10 (International Classification of Diseases, Version 10) categories as listed in Chapter V Mental and Behavioral Disorders of the World
Health Organization (WHO). Among the 43 studies, we found two on organic mental disorders [F0], nine on psychoactive substance abuse [F1], five on schizophrenia [F2], 24 on affective disorders (including suicide) [F3], and three on neurosis [F4]. Not a single study was found in the five remaining categories (F50-F59 Behavioral syndromes associated with physiological disturbances and physical factors, F60-F69 Disorders of adult personality and behavior, F70-F79 Mental retardation, F80-F89 Disorders of psychological development, and F90-F98 Behavioral emotional disorders with onset usually occurring in childhood or adolescence). Table 2 presents the findings from the 43 studies. In summary, $72 \%$ reported a positive relationship between R/S and better mental health, 19\% found mixed (positive and negative) results, $2 \%$ indicated no association, $5 \%$ found a negative association. In other words, $93 \%$ of the studies found at least one positive association (significant, trend, or mixed), , whereas $23 \%$ reported at least one negative relationship. All studies on dementia [F0], suicide [F3] and neurosis [F4] found at least positive association between R/S and mental health, as well as $79 \%$ of the studies on depression [F3] and $67 \%$ of those on substance abuse. In contrast, most findings in schizophrenia [F2] were mixed or positive, whereas those in bipolar disorder [F31] were negative or mixed.

Table I Quality analysis and study outcomes of the 43 papers

\begin{tabular}{|c|c|c|c|c|c|c|c|}
\hline Author,Yr & Journal & No. Subjects & Design & Methods & Statistics & QS & Finding \\
\hline \multicolumn{8}{|c|}{ F00-F09 Organic, including symptomatic, mental disorders } \\
\hline Kaufman $(2007)^{4}$ & Neurology & 70 & prospective & very good & very good & 8 & POS \\
\hline Coin $(2010)^{5}$ & Curr Alzheimer Res & 64 & prospective & excellent & excellent & 9 & POS \\
\hline \multicolumn{8}{|c|}{ FI0-FI 9 Mental and behavioral disorders due to psychoactive substance abuse } \\
\hline Francis $(1993)^{23}$ & Addiction & 4,753 & cross-sectional & very good & fair & 5 & POS \\
\hline Mullen $(1996)^{25}$ & Addiction & 985 & cross-sec \& prosp & fair & fair & 3 & POS \\
\hline Kendler (1997) $)^{18}$ & Am J Psychiatry & 1,902 & cross-sec \& retrosp & excellent & excellent & 9 & POS \\
\hline Miller $(2000)^{19}$ & JAACP & 676 & cross-sectional & excellent & excellent & 8 & POS \\
\hline Kendler $(2003)^{20}$ & Am J Psychiatry & 2,616 & cross-sec \& retrosp & very good & fair & 6 & POS \\
\hline Blay $(2008)^{26}$ & Am J Geriatr Psychiatr & 6,961 & cross-sectional & very good & very good & 8 & MIX \\
\hline Chi $(2009)^{22}$ & Addiction & 357 & cross-sec \& prosp & good & very good & 7 & MIX \\
\hline Ghandour (2009) ${ }^{24}$ & Addiction & I,837 & cross-sec \& retrosp & good & good & 6 & POS \\
\hline Harden $(2010)^{21}$ & J Child Psychol Psych & 5,348 & cross-sec \& prosp & excellent & excellent & 9 & NA \\
\hline \multicolumn{8}{|c|}{ F20-F29 Schizophrenia, schizotypal and delusional disorders } \\
\hline Nimgaonkar $(2000)^{27}$ & Am J Psychiatry & 8,542 & retrosp cohort & very good & very good & 8 & POS \\
\hline Mohr $(2006)^{28}$ & Am J Psychiatry & 115 & cross-sectional & good & good & 6 & POS \\
\hline Moss $(2006)^{31}$ & Schizophrenia Res & 195 & cross-sec\& retrosp & good & very good & 7 & MIX \\
\hline Borras $(2007)^{30}$ & Schizophrenia Bull & 103 & cross-sectional & good & fair & 6 & MIX \\
\hline Linden $(2010)^{29}$ & Psychollogical Med & n.a. & retrosp cohort & very good & very good & 8 & NEG \\
\hline \multicolumn{8}{|c|}{ F3 I Bipolar affective disorder } \\
\hline Mitchell $(2003)^{33}$ & JAffect Disord & 147 & cross-sectional & fair & fair & 5 & MIX \\
\hline Cruz $(20 \mid 0)^{41}$ & Bipolar Disord & 334 & cross-sectional & good & good & 6 & NEG \\
\hline \multicolumn{8}{|c|}{ F32 Depressive episode and F33 Recurrent depressive disorder } \\
\hline Pressman $(1990)^{34}$ & Am J Psychiatry & 30 & cross-sectional & good & fair & 6 & POS \\
\hline Koenig $(1992)^{35}$ & Am J Psychiatry & 850 & cross-sec \& prosp & excellent & very good & 9 & POS \\
\hline Azhar $(1995)^{49}$ & Psychother Psychosom & 64 & random clin trial & fair & good & 5 & POS \\
\hline Miller $(1997)^{45}$ & JAACAP & 211 & prospective & very good & very good & 8 & POS \\
\hline Braam $(1997)^{52}$ & Acta Psychiatr Scand & 177 & prospective & very good & good & 7 & POS \\
\hline Koenig $(1997)^{43}$ & Am J Geriatr Psychiatr & 4,000 & cross-sectional & very good & very good & 8 & POS \\
\hline Koenig $(1998)^{36}$ & Am J Psychiatry & 86 & prospective & very good & very good & 9 & POS \\
\hline Braam (1999) ${ }^{40}$ & JAffect Disord & 3,051 & cross-sectional & very good & very good & 7 & MIX \\
\hline Braam $(200 I-I)^{37}$ & Psychol Med & 8,398 & cross-sectional & very good & very good & 8 & POS \\
\hline Braam $(200 \mathrm{I}-2)^{39}$ & Psychol Med & 17,739 & cross-sectional & very good & very good & 8 & POS \\
\hline Miller $(2002)^{46}$ & JAACAP & 3,356 & cross-sectional & very good & good & 7 & POS \\
\hline Horowitz $(2003)^{47}$ & JAACAP & 240 & prospective & very good & good & 7 & (POS) \\
\hline Nasser $(2005)^{51}$ & Acta Psychiatr Scand & 62 & cross-sec/prosp & good & very good & 6 & POS \\
\hline King $(2007-1)^{38}$ & Psychol Med & 709 & cross-sectional & good & very good & 7 & MIX \\
\hline
\end{tabular}


Table Continued..

\begin{tabular}{|c|c|c|c|c|c|c|c|}
\hline Author,Yr & Journal & No. Subjects & Design & Methods & Statistics & QS & Finding \\
\hline King $(2007-2)^{38}$ & Psychol Med & 402 & prospective & very good & very good & 7 & MIX \\
\hline Koenig $(2007)^{42}$ & Am J Geriatr Psychiatr & $\mathrm{I}, 424$ & case-control & very good & very good & 7 & POS \\
\hline Chatters $(2008)^{44}$ & Am J Geriatr Psychiatr & 837 & cross-sectional & very good & very good & 8 & POS \\
\hline Cruz (2009) ${ }^{41}$ & Am J Geriatr Psychiatr & 130 & cross-sectional & good & good & 5 & POS \\
\hline Maselko $(2009)^{50}$ & Psychol Med & 918 & cross-sec \& retrosp & very good & fair & 6 & POS \\
\hline Braam $(20 \mid 0)^{52}$ & J Affect Disord & 776 & cross sectional & very good & very good & 8 & MIX \\
\hline $\operatorname{Dew}(2010)^{48}$ & J Affect Disord & 145 & cross-sec \& prosp & very good & very good & 7 & POS \\
\hline \multicolumn{8}{|l|}{ Suicide } \\
\hline Neeleman $(1997)^{53}$ & Psychol Med & 28,085 & cross-sectional & excellent & very good & 10 & POS \\
\hline Dervic $(2004)^{54}$ & Am J Psychiatry & 371 & cross-sectional & good & good & 7 & POS \\
\hline Rasic $(2009)^{55}$ & J Affect Disord & 36,984 & cross-sectional & excellent & very good & 9 & POS \\
\hline \multicolumn{8}{|c|}{ F40-F48 Neurotic, stress-related and somatoform disorders } \\
\hline Azhar $(1994)^{56}$ & Acta Psychiatr Scand & 62 & random clin trial & good & good & 5 & POS \\
\hline Azhar $(1995)^{58}$ & Acta Psychiatr Scand & 30 & random clin trial & good & good & 5 & POS \\
\hline Kaplan $(2005)^{57}$ & J Clin Psychiatry & 314 & cross-sectional & very good & good & 8 & POS \\
\hline
\end{tabular}

QS: Quality Score; MH: Mental Health; POS: Significant; (POS):Trend; NA: No Association; MIX: Mixed; NEG: Significant; (NEG):Trend

Table 2 Overview of results

\begin{tabular}{|c|c|c|c|c|c|c|}
\hline & POS & (POS) & NA & MIX & (NEG) & NEG \\
\hline & n (\%) & n (\%) & n (\%) & n (\%) & n (\%) & n (\%) \\
\hline F0 Dementia & $2(100)$ & 0 & 0 & 0 & 0 & 0 \\
\hline FI Addiction & $6(67)$ & 0 & $\mathrm{I}(\mathrm{II})$ & $2(22)$ & 0 & 0 \\
\hline F2 Schizophrenia & $2(40)$ & 0 & 0 & $2(40)$ & 0 & 0 \\
\hline F3 Depression & I5 (79) & I (5) & 0 & $3(16)$ & 0 & I (20) \\
\hline F3 Suicide & $3(100)$ & 0 & 0 & 0 & 0 & 0 \\
\hline F3 Bipolar & 0 & 0 & 0 & I (50) & 0 & 0 \\
\hline F4 Neurosis & $3(100)$ & 0 & 0 & 0 & 0 & I (50) \\
\hline All disorders & 31 (72) & I (2) & I (2) & $8(19)$ & 0 & $2(5)$ \\
\hline
\end{tabular}

POS: Significant; (POS):Trend; NA: No Association; MIX: Mixed; NEG: Significant; (NEG):Trend

\section{Specific studies}

Organic mental disorders: Two studies were in the category F00-F09 Organic Mental Disorders, ${ }^{4,5}$ and had many characteristics in common. Both focused on Alzheimer's disease [F00], both used a sound methodology for making the diagnosis, both examined religiosity as the primary predictor, both were prospective, and both were rated high for quality of design and statistical methods. Both studies measured cognitive decline over 12 months with the Minimental State Examination (MMSE). Both study populations had a mean age of about 78 years and had more female than male subjects. Finally, both studies reported that higher levels of R/S correlated with slower cognitive decline over time.

The first study by Kaufman et al., ${ }^{4}$ examined the effects of two religious variables on annual MMSE decline, a self-rating of spirituality and frequency of private religious activities (prayer, Bible study, meditation, etc.). These predictors accounted for $16.5 \%$ of the variance in annual MMSE score in a multiple regression model. In contrast, both measures of quality of life, i.e. the Visual Analog Scale from the EuroQOL EQ5D instrument and the Quality of Life in AD scale, did not predict rate of cognitive decline. The second study by Coin et al., ${ }^{5}$ had a slightly more cognitively-impaired sample (baseline MMSE 20.7) compared to the Kaufman study (23.6). Not only did these researchers measure cognitive decline, but also included functional and behavioral measures. The authors formed two groups, based on a measure of religiosity that included religious attendance, praying, reading religious literature, and watching/listening to religious programs on TV or radio: 35 subjects were of moderate or high religiosity and 29 of no or low religiosity. Cognitive, functional and behavioral scores did not differ significantly between the two groups at baseline. However, a year later, the high religiosity group showed no significant decline in cognitive and behavioral scores, while the low religiosity group scored significantly worse on both. However, all patients experienced a progressive decline in functional abilities. The paper also examined caregiver burden, finding a significant reduction over time in caregivers of religious patients.

Substance abuse: Nine studies were in the category F10-F19 Psychoactive Substance Abuse ${ }^{18-26}$. Out of the nine subcategories in F10-F19, six of them were covered by the studies found. All nine papers focused on alcohol abuse [F10], two of them exclusively ${ }^{21,24}$, three on nicotine dependency [F17] ${ }^{18,25,26}$, and four on other forms of substance abuse, ${ }^{19,20,22,23}$ examining use of heroin [F11 23], marijuana [F12 19,23], cocaine [F14 19], nicotine [F17 20,23], butane gas [F18 23], glue [F18 23], "drug abuse" in general ${ }^{20,22}$, and "any contraband drug". ${ }^{19}$ Three of the nine subcategories were not covered: there were no studies on the use of sedatives or hypnotics [F13], other stimulants, including caffeine [F15], and hallucinogens.[F16] Four papers focus on adolescents, ${ }^{19,21-23}$ another four on adults, ${ }^{18,20,24,25}$ and one in a geriatric population. ${ }^{26}$ Two papers were based on the populationbased Virginia Twin Registry, ${ }^{18,20}$ both of them including several other lifetime psychiatric disordersbesides substance abuse in their analysis. One study only had female participants. ${ }^{18}$ All nine studies except one ${ }^{21}$ found an inverse relationship between R/S and substance abuse, and one study found an inverse relationship with drug dependency but not with alcohol misuse. ${ }^{22}$ The findings in the five substances studied [F11, F12, F14, F17,] and [F18] besides alcohol all reported inverse relationships between $\mathrm{R} / \mathrm{S}$ and substance abuse.

The only study in this group that found no association between substance abuse and $\mathrm{R} / \mathrm{S}$ was the most recent publication with the largest sample, published by Harden ${ }^{21}$ on the age at first onset of drinking, using twins and siblings (aged 11 to 21 years) who 
were concordant or discordant for religiosity. In this dataset of 5,348 individuals, the mean age at drinking initiation for the 'Both Religious' group (14.4 years) was slightly but significantly later than for the 'Both Non-Religious' group (13.9 years). In the case of religious discordance between the siblings, however, the mean age at first drink for the 'Self Religious Only' group (14.2) was equal to the mean age at first drink for the 'Sibling Religious Only' group (14.2), indicating that siblings who differed in their religiosity both drink earlier in a non-religious family and later in a non-religious family. The author concluded that individual religious involvement might a proxy variable for family or cultural environments, although admits that the religiosity of the family may provide an environment that helps to delay the onset of drinking.

Kendler et al., ${ }^{18}$ analyzed data from 1,902 female twins (mean age 30). All three R/S dimensions (personal devotion and personal and institutional conservatism) were significantly and inversely associated with current levels of drinking and smoking as well as with lifetime risk for alcoholism and nicotine dependence. The study by Miller et al., ${ }^{19}$ examined male and female adolescents (aged 15 to 19 years), finding that $\mathrm{R} / \mathrm{S}$ and substance abusewere again inversely correlated. The $\mathrm{R} / \mathrm{S}$ items were inversely associated with substance use and substance dependence or abuse across a range of substances (alcohol, marijuana, cocaine, or any contraband drug). Three years later, Kender published another study out of the population-based Virginia Twin Registry, ${ }^{20}$ although the response rate was only $36 \%$. Developing a $\mathrm{R} / \mathrm{S}$ questionnaire consisting of 78 items from which they identified seven factors, they found that most R/S factors reduced the risk for drug abuse ( 6 of $7 \mathrm{R} / \mathrm{S}$ factors), nicotine dependence (5 of 7), and alcohol dependence (5 of 7). Moreover, some R/S factors reduced the risk for adult antisocial behavior (4 of 7), major depression (3 of 7), phobias ( 3 of 7), panic disorder (2 of 7), and bulimia nervosa (2 of 7). Interestingly, one R/S factor ("general religiosity") increased the risk for generalized anxiety disorder (although in these crosssectional analyses, anxiety symptoms may have caused an increase in religiosity to cope with the anxiety).

Francis et al., ${ }^{23}$ studied adolescents (13-15 year of age) regarding their attitudes towards the use of alcohol, butane gas, glue, heroin, marijuana and tobacco, and correlated those with indices of religious affiliation, belief and practice. ${ }^{23}$ In this British sample, 24\% indicated that they were atheists, 33\% agnostics, and only $43 \%$ believers. Religiosity was a significant predictor of attitudes towards the use of each of the above substances. Another adolescence study was conducted by Chi et al., ${ }^{22}$ who analyzed data on 13-18 year olds in northern California. These youth were involved in a chemical dependency treatment program and completed both baseline and 3 -year follow-up interviews. ${ }^{22}$ The researchers focused on 12-Step involement, not religiosity. Frequency of religious service attendance was associated with drug but not alcohol abstinence. Social support and religious service attendance may have mediated the relationship between post-treatment 12-Step affiliation and 3-year outcomes. In a study that focused on use of tobacco and alcohol, Blay and coworkers ${ }^{26}$ examined associations with four R/S characteristics in a geriatric sample. Not having a religious affiliation increased the risk of tobacco use by $124 \%$ and the risk of alcohol misuse or dependence by $88 \%$. All four religious domains were inversely related to tobacco use, but none to alcohol misuse.

Lilian Ghandour et al., ${ }^{24}$ examined the role of religiosity in alcohol use disorders in Christian (58\%), Druze (5\%) and Muslim (37\%) university students (average: 20 years) living in Lebanon. Believing in God and practising one's faith were related inversely to alcohol abuse and dependence in all religious groups, including "ever" drinkers (belief in God only). Finally, Mullen et al., ${ }^{25}$ quantitatively and qualitatively examined the drinking and smoking habits of adult Scots of Irish descent compared with other Scots. They examined denominational affiliation (protestant, catholic, non-religous) only. To assess the associations between current religious affiliation and social class, a series of log-linear analyses were conducted on each of the dependent health behavior variables, finding that the non-religious were more prone to be moderate to heavy drinker than Protestants or Catholics.

Psychotic disorders: Five studies were in the F20-F29 Schizophrenia, Schizotypal and Delusional Disorders category. ${ }^{27-31}$ Most examined patient with disorders within the overall group [F20-F29], although one study focused on Acute and transient psychotic disorders.[F23 29] The latter reported that intensive $R / S$ experiences increased the likelihood of relatively transient psychotic disorders, whereas the four remaining publications reported that $\mathrm{R} / \mathrm{S}$ was related to greater compliance or higher well-being in schizophrenic patients.

The one study reporting that intensive R/S experiences had an adverse effect on psychosis was based on a retrospective case-notes analysis conducted by the Linden group. ${ }^{29}$ In early twentieth-century Protestant countries, a series of religious revivals centered on traveling preachers generated intense religious experiences and enthusiasm. The most dramatic of such revivals in North Wales occurred in 19041905. Linden et al., ${ }^{29}$ analyzed the case-notes of patients admitted to North Wales hospitals during this period, and found significantly more brief polymorphic psychoses (F23), while the number of other mental disorders did not change. The vast majority of these admissions was linked to revival meetings during this period; interestingly, these psychoses were largely transient and did not result in further admissions.

Nimgaonkar et al., ${ }^{27}$ however, found a significantly lower prevalence of schizophrenia and other functional psychoses among the Hutterites (vs. the total population of Manitoba, Canada). Hutterites are an Anabaptist Christian sect that originated in the Austrian Alps in about 1528. There was also a lower prevalence of affective psychoses and adjustment disorders in this group, although rates for neurotic disorders were elevated. R/S may also influence compliance and well-being in patients with schizophrenia. Mohr et al., ${ }^{28}$ administered a semi-structured interview to a sample of 115 outpatients with psychotic illnesses in Switzerland. For $71 \%$ of the patients, R/S instilled hope, purpose, and meaning in their lives, whereas for $14 \%$, it induced spiritual despair. More patients also reported that R/S lessened psychotic and general symptoms, increased social integration, reduced the risk of suicide attempts, and reduced substance use. In another report a year later from this same sample, ${ }^{30}$ investigators divided patients into adherent $(\mathrm{n}=59)$ and non-adherent $(n=44)$ groups (regarding medication use). Religious involvement was divided in to three categories: non-religious; spiritual, but nonpracticing collectively; and religious (practicing collectively at least once a month). The more that religion was important in patients' lives, the less patients were substance abusers and the more likely they were in symptomatic remission. Adherent patients were significantly more likely than non-adherent patients to belong to the religious group. A report by Moss et al., ${ }^{31}$ indicated similar findings. They found that in patients with at least one psychotic symptom(delusions, hallucinations, or prominent thought disorder), the time to first treatment and time to first hospitalization were both inversely related to degree of religious practice (suggesting that religious practices might have reduced the time from symptom onset to receiving treatment).

In contrast, the Mohr study above found that $\mathrm{R} / \mathrm{S}$ could either foster adherence to $(16 \%)$ or opposition to $(15 \%)$ psychiatric treatment. 
Similarly, Moss et al. ${ }^{31}$ had found a longer duration of untreated psychosis in the Protestant group compared to those with no affiliation. Borras et al., ${ }^{36,30}$ using the same sample as Mohr et al, found that nonadherent patients made up most of the "spiritual but not collectively practicing" group. In that report, $31 \%$ of non-adherent patients emphasized an incompatibility between their religious convictions, medication use, and supportive therapy, compared to $8 \%$ of adherent patients. This suggests that $\mathrm{R} / \mathrm{S}$ could lead to noncompliance if not collectively practiced.

Depression: Of the 43 papers, 24 were in the F30-F39 Mood (affective) Disorders category. these, two studies were in the F31 Bipolar affective disorder ${ }^{32,33}$ group and 19 in the F32 Depressive episode or F33 Recurrent depressive disorder categories. ${ }^{34-52}$ No studies, however, were found in the F30.0 Hypomania, F34 Persistent mood disorders (i.e. Cyclothymia, Dysthymia, etc.), F38 Other mood disorders, or F39 Unspecified mood disorder groups. We also included three studies on suicide ${ }^{53-55}$ in this section.

Both studies on bipolar affective disorder [F31] reported an association between R/S. The study of Mitchell \& Romans ${ }^{33}$ found that most patients saw a direct link between their beliefs and the management of their illness, and many used religion to cope with their symptoms. However, a significant minority also indicated that their R/S beliefs put them in conflict with illness models (24\%) and the advice (19\%) provided by their medical advisors. Six out of 147 patients described a conflict due to a spiritual leader telling them that they did not need their medications anymore as they had been cured spiritually. Moreover, Cruz et al., ${ }^{32}$ found increased rates of prayer/ meditation in bipolar patients who were in a mixed state, and lower rates of prayer/meditation in patients who were euthymic. Depression and mania were not associated with religious involvement.

While the role that $\mathrm{R} / \mathrm{S}$ plays in bipolar disorder is unclear or negative, the results reported by the three studies on $\mathrm{R} / \mathrm{S}$ and suicidality are consistently in the positive direction (i.e., an inverse relationship with suicide). Neeleman et al., ${ }^{53}$ examined ecological associations between suicide tolerance, religion and suicide rates. Data were collected by interviews of random samples of adult residents of 19 Western countries (Europe, USA, Canada) in 1989/90. These data were compared with the actual suicide rates of those countries in 1989. They found that the USA and Ireland scored the highest on religiousness, whereas Sweden and Denmark lowest on religiousness; Northern Ireland and Ireland, in turn, scored the lowest and the Netherlands highest on tolerance to suicide. Overall, there was a negative association between religiousness and suicide tolerance (stronger in women than men), and higher levels of suicide tolerance were associated with higher suicide rates. Finally, higher levels of religiousness, church attendance and religious upbringing were associated with lower suicide rates in women, but not in man.

Rasic et al., ${ }^{55}$ examined relationships between spiritual values, religious attendance, and 12-month suicide ideation and suicide attempt in the Canadian Community Health Survey. They found that $0.47 \%$ of religious and $0.83 \%$ of non-religious persons committed at least one suicide attempt in the past 12 months. "Identifying oneself as spiritual" and "religious attendance" were both significantly associated with a decreased likelihood of suicide attempt. After adjusting for social supports, religious attendance remained a significant predictor. Finally, Dervic et al.,${ }^{54}$ interviewed 371 depressed inpatients, finding no differences in depression, hopelessness, or stressful life events between religious and non-religions patients. However, religiously unaffiliated subjects had significantly more lifetime suicide attempts and more first-degree relatives who committed suicide than subjects with a religious affiliation. Furthermore, subjects with no religious affiliation perceived fewer reasons for living, particularly fewer moral objections to suicide. In addition, religiously unaffiliated subjects had more lifetime impulsivity, aggression, and were more likely to have a past history of substance use disorder.

Research of the relationship between $\mathrm{R} / \mathrm{S}$ and depression is the most developed. Eleven of the 19 studies examined a geriatric sample, ${ }^{34-44}$ four papers focused on adolescents, ${ }^{45-48}$ and four studies examined adults. ${ }^{49-52}$ Four focused on depression in the medically ill, ${ }^{34-36,42}$ two on religious coping, ${ }^{35,52}$ two had only female participants, ${ }^{34,46}$ and two examined on mother-offspring relationships. ${ }^{45,47}$ Five of the 19 studies examined psychiatric patients, ${ }^{36,41,48,49}$ and only two those were in psychiatric inpatients. ${ }^{41,51}$ The vast majority examined a representative population-based sample focusing on the prevalence of depression. With regard to the relationship between $\mathrm{R} / \mathrm{S}$ and depression, five studies reported mixed results, ${ }^{38,40,47,48,52}$ whereas the other 13 papers found a positive relationship between $\mathrm{R} / \mathrm{S}$ and depression (i.e., less depression among those who were more R/S). All 18 studies reported at least one positive finding, none found no association or only a negative association. what did the 19th study find?

Three of the studies reported mixed results. Two found a U-shaped association, so that very high religiosity and very low religiosity were prone to more depression. First, Braam et al. ${ }^{40}$ found more depressive symptoms older Dutch citizens (55-85 years) in a hyperconservative religious climate, examined on the municipality level, using percentages of votes for hyperconservative political parties. Second, King et al. ${ }^{38}$ found in their cross-sectional and longitudinal analyses of 709 primary care elders more depressive symptoms in those with very high compared to those with moderate levels of private religiosity. This U-shaped relationship between $\mathrm{R} / \mathrm{S}$ and depression should be a focus of future studies, since it was not addressed in any of the other papers. The third study with mixed results reported by Braam et al., ${ }^{52}$ found that positive religious coping was not associated with depressive symptoms. Moreover, there was a significant positive correlation between sub-threshold depression and positive religious coping. The remaining 15 studies all reported only a positive correlation between $\mathrm{R} / \mathrm{S}$ and depression.

Of the five studies that involved psychiatric patients, one was a randomzied clinical trial involving the use of religious psychotherapy in 64 Muslim patients with depression. ${ }^{49}$ Patients in the study group showed more rapid improvement during the initial 3 months of the study than those in the control group, although at the end of the 6 months the difference became nonsignificant.

Nasser et al., ${ }^{51}$ found that depression severity was negatively correlated with spiritual support at baseline in 62 psychiatric inpatients. However, spiritual support did not predict a decrease in depressive symptoms at 3-month follow-up. In a study of 130 patients with late-life depressions, Cruz et al., ${ }^{41}$ found significant negative associations between frequency of prayer/meditation and depression as well as between prayer/meditation and hopelessness.

Similarly, Koenig et al., ${ }^{36}$ studied the effects of R/S on remission of depression in 86 medically ill hospitalized older patients. Intrinsic religiosity predicted a shorter time to remission, but church attendance and private religious activities did not. Dew et al., ${ }^{48}$ studying 145 depressed adolescents (12-18 year of age) found that daily spiritual experiences, forgiveness, positive religious coping, positive religious support, less loss of faith, organizational religiousness, and selfranking as R/S were all negatively related to depression in the crosssectional analysis. As expected, negative religious coping, negative religious support, and loss of faith were all positively related to depression. In their longitudinal analyses, a loss of faith predicted less improvement in depression scores over 6 months. 
Three papers focus on the incidence of depression in a medically ill population what about the Koenig study ${ }^{35}$ above; why not include that? Shouldn't that study be in this section? Also, why isn't the Dew et al., ${ }^{47}$ study included in the section about adolescents?]: Pressman et al., ${ }^{34}$ examine a small sample elderly women recovering from surgical repair of a broken hip, finding that $\mathrm{R} / \mathrm{S}$ was cross-sectionally associated with lower levels of depressive symptoms. Koenig et al., ${ }^{35}$ examined the frequency of religious coping among older medical inpatients; $20 \%$ reported that $\mathrm{R} / \mathrm{S}$ was the most important strategy used to cope with illness. Depressive symptoms were inversely related to religious coping, an association which persisted after controlling for other sociodemographic and health correlates. When a subsample was re-evaluated after 6 months, religious coping was the only baseline variable that predicted lower depression scores at follow-up. In another study, the same group ${ }^{42}$ examined medical inpatients over age 50, finding that depressed participants were more likely to indicate no religious affiliation, less likely to affiliate with neofundamentalist denominations, more likely to indicate "spiritual but not religious," less likely to pray or read scripture, and scored lower on intrinsic religiosity. Among depressed patients, there was no relationship between religion and depression type, but religious attendance, prayer, scripture reading, and intrinsic religiosity were associated with less depression severity.

Three studies focus on the incidence of depression in the adolescents. Miller et al., ${ }^{45}$ found that maternal religiosity and mother-offspring concordance on religious denomination tended to be protective against depression in offspring, assessing their study cohort over the course of a 10-year follow-up. The association was independent of maternal parental bonding, maternal social functioning, and maternal demographics. In another report, the same group $^{46}$ found that personal devotion and participation in religious community were associated with a decreased likelihood of depression in non-highly mature girls and an even greater decrease in likelihood of depression in highly mature girls. Finally, Horowitz et al. ${ }^{47}$ found that depressive episodes during grades 7 through 11 predicted lower religious attendance during 12 th grade in adolescents, controlling for prior religiosity. However, they found that $\mathrm{R} / \mathrm{S}$ did not moderate the relation between chronicity of maternal depression and depressive disorders in adolescents.

Six studies focusd on the depression in a geriatric population. Braam et al., ${ }^{39}$ found in a community-based sample that religious salience was not associated with incidence of depression, but showed a strong association with improvement of depression among the respondents who were depressed at the first measurement. This association was most prominent among subjects with poor physical health. Two years later they found high levels of depressive symptoms in non-religious political climate, and a lower level in moderate and -conservative political climates. ${ }^{40}$ Later, the same group ${ }^{37}$ examined whether the prevailing religious climate was related to cross-cultural differences in depression among elderly Europeans. Study I consisted involved six study centers, and study II involved 13. In the first study, depression rates were lower among regular church-attenders, most prominently among Catholics. In the second study, fewer depressive symptoms were found among the female elderly in countries, generally Catholic, with high rates of regular church-attendance. However, higher levels of depressive symptoms were found among the male elderly in Protestant countries in that study. King et al., ${ }^{38}$ also found an inverse linear relationship of depressive symptoms with private religious involvement in primary care patients over age 65. In their longitudinal analyses, they reported that subjects indicating moderate levels of private religiosity at baseline experienced lower levels of depressive symptoms at 1-year follow-up compared to those reporting low levels of private religious activity. Koenig et al., ${ }^{43}$ found in a sample of 4,000 persons age 65 and over, that frequency of church attendance was negatively related to depression. Frequent churchgoers were about half as likely to be depressed. In contrast, private prayer/ Bible reading was unrelated to depression, and religious TV/radio listening was positively related with depression. Finally, Chatters et al., ${ }^{44}$ examined data on religious involvement and depression from the National Survey of American Life, using a subsample of African American aged 55 years or older; results indicated that religious service attendance was significantly and inversely associated with the likelihood of having a lifetime mood disorder.

The last two studies focus on the depression in an adult population. Braam et al., ${ }^{52}$ found that daily prayer and weekly religious attendance were negatively associated with depressive symptoms. Maselko et al., ${ }^{50}$ reported that religious service attendance was associated with $30 \%$ lower odds of depression in the New England Family Study cohort (mean age $=39$ years). However, higher levels of religious wellbeing were associated with 1.5 times higher odds of depression (but only after controlling for existential well-being).

Neuroses: For Neurotic, Stress-related and Somatoform Disorders (F40-F48), we found only three studies during the last 20 years. One study was found on F41 Other anxiety disorders (F41.1 Generalized anxiety disorder, ${ }^{56}$ ) and two studies were identified on F43 Reaction to severe stress, and adjustment disorders (both on F43.1 Posttraumatic stress disorder. ${ }^{57,58}$ ) No studies were identified on F40 Phobic anxiety disorders group, F42 Obsessive compulsive disorder, F44 Dissociative disorders, F45 Somatoform disorders, or F48 Other neurotic disorders groups.

Azhar et al., ${ }^{56}$ conduced a randomized clinical trial in religious Muslim patients with generalized anxiety disorder. Those in the intervention group received religious psychotherapy in addition to supportive psychotherapy and anxiolytic drugs, and were compared with those in the control group that received only supportive psychotherapy and anxiolytic drugs. Those receiving religious psychotherapy showed significantly more rapid improvement in anxiety symptoms than those who received supportive psychotherapy and drugs only. The same group ${ }^{58}$ one year later conducted a second randomized clinical trial in bereaved Muslim patients, comparing those who received psychotherapy with a religious perspective with those receiving traditional secular psychotherapy. The patients in the religious psychotherapy group showed significantly greater improvement compared to those in the control group at the end of 6 months.

One of the most interesting studies, however, comes from a Jewish sample ${ }^{57}$ in Israel. Investigators found that highly religious inhabitants from the Gaza Strip, in spite of firsthand daily exposure to violent attacks, reported the fewest and least severe symptoms of stress-related complaints, the least sense of personal threat, and the highest level of functioning among the three groups compared. The most severely symptomatic and functionally compromised group were secular inhabitants of a Tel-Aviv suburb, who were the least frequently and least directly affected by exposure to violent attacks. The religious inhabitants of the West Bank (third group) had almost the same symptom profile as the Gaza Strip population, whereas secular inhabitants of West Bank reported faring worse than did either population in the Tel-Aviv suburb.

\section{Discussion}

The present study systematically identified 43 research studies that examined relationships between $\mathrm{R} / \mathrm{S}$ and mental disorders between 
1990 and 2010, reporting on the quality of the design and methods and summarizing the results. This article serves as a follow-up to the Larson et al review that examined the studies published in the previous 13 years from 1978 through 1989. ${ }^{3}$ Interestingly, despite differences in methodology, we largely replicated Larson's findings. During the two decades after his research, we found that about $70 \%$ of studies found significant positive associations between religious involvement and better mental health. We believe that our methodology - choosing only articles published in the top $25 \%$ psychiatric journals - improves on the methodology of Larson who included articles from only two top psychiatric journals. Moreover, we presented our results by psychiatric diagnoses and rated each study according to quality. Not all of the publications were of the best methodology, but many of them were, suggesting that further research on $\mathrm{R} / \mathrm{S}$ and mental disorders is warranted.

If nothing else, this report questions the conclusions of a review of this area published in the American Journal of Psychiatry in 1969, in which the reviewer stated: "The contention that religion as an institution has been instrumental in fostering general well-being, creativity, honesty, liberalism, and other qualities is not supported by empirical data. Both $\operatorname{Scott}^{55} \& \operatorname{Godin}^{22}$ point out that there are no scientific studies which show that religion is capable of serving mental health" (p 1203). ${ }^{59}$

The findings in the present report are notable, given the general neglect of this topic in many top tier journals: $41 \%$ of psychiatry and $69 \%$ of neurology journals did not publish any R/S research during the period we reviewed. This is remarkable given that research on $\mathrm{R} / \mathrm{S}$ and health has increased dramatically in the past 20 years, with close to 2,500 original data-based quantitative reports published during this period, three-quarters addressing $\mathrm{R} / \mathrm{S}$ and mental health. ${ }^{60}$ In 1986, Larson et al., ${ }^{2}$ reviewed 2,348 quantitative studies in four major psychiatric journals between 1978 and 1982, of which only 59 included a quantifiable religious variable (2.5\%), 37 of those assessing denomination only. They concluded that the religious variable was "the forgotten factor" in psychiatric research. It seems that this is still the case after 25 years.

There is good evidence today that $\mathrm{R} / \mathrm{S}$ is correlated with mental health in three major domains of psychiatry: depression, substance abuse, and suicide. There is insufficient evidence, although positive, for two other domains: neurosis and organic mental disorder. Only a few and conflicting results were found for the domains of bipolar disorder and schizophrenia. Finally, there is no evidence of an association between $\mathrm{R} / \mathrm{S}$ and other psychiatric disorders such as eating disorders, sexual disorders, phobic anxiety disorders, obsessivecompulsive disorders, dissociative disorders, somatoform disorders, and personality disorders, at least in top tier psychiatric and neurology journals.

\section{Conclusion}

In conclusion, there numerous studies published over the past 20 years that have examined connections between R/S and mental health, and over three dozen of those have been published in high quality journals in psychiatry and neurology, the majority of which find a positive association between R/S and better mental health. Most are cross-sectional in design, and chronic mental disorders have often received the least attention. Further research is needed, both on mental disorders that have thus far been neglected and on developing interventions that may help boost the positive religious resources of patients to help them cope better with their diseases or possibly influence the course of their diseases.

\section{Acknowledgments}

None.

\section{Conflicts of interest}

None.

\section{Funding}

None.

\section{References}

1. Koenig HG. Research on religion, spirituality, and mental health: a review. Can J Psychiatry. 2009; 54(5):283-291.

2. Larson DB, Pattison EM, Blazer DG, et al. Systematic analysis of research on religious variables in four major psychiatric journals, 19781982. Am J Psychiatry. 1986;143(3):329-334

3. Larson DB, Sherrill KA, Lyons JS, et al. Associations between dimensions of religious commitment and mental health reported in the American Journal of Psychiatry and Archives of General Psychiatry: 1978-1989. Am J Psychiatry. 1992;149(4):557-559.

4. Kaufman Y, Anaki D, Binns M, et al. Cognitive decline in Alzheimer disease: Impact of spirituality, religiosity, and QOL. Neurology. 2007;68(18):1509-1514

5. Coin A, Perissinotto E, Najjar M, et al. Does religiosity protect agains cognitive and behavioral decline in Alzheimer's dementia? Curr Alzheimer Res. 2010;7(5):445-452.

6. Tsuang MT, Williams WM, Simpson JC, et al. Pilot study of spirituality and mental health in twins. Am J Psychiatry. 2002;159(3):486-488.

7. Winter U, Hauri D, Huber S, et al. The psychological outcome of religious coping with stressful life events in a Swiss sample of church attendees. Psychother Psychosom. 2009;78(4):240-244.

8. Rammohan A, Rao K, Subbakrishna DK. Religious coping and psychological wellbeing in carers of relatives with schizophrenia. Acta Psychiatr Scand. 2002;105(5):356-362.

9. Hebert RS, Dang Q, Schulz R. Religious beliefs and practices are associated with better mental health in family caregivers of patients with dementia: findings from the REACH study. Am J Geriatr Psychiatry. 2007;15(4):292-300

10. Bishop FL, Barlow F, Walker J, et al. The development and validation of an outcome measure for spiritual healing: a mixed methods study. Psychother Psychosom. 2010;79(6):350-362.

11. Borg J, Andree B, Soderstrom H, et al. The serotonin system and spiritual experiences. Am J Psychiatry. 2003;160(11):1965-1969.

12. Jones E, Watson JP. Delusion, the overvalued idea and religious beliefs: a comparative analysis of their characteristics. Br J Psychiatry. 1997; 170:381-386

13. Trindade PC, Simonaggio RG, Fernandes LF, et al. Religiosity and gender differences among Brazilian schizophrenic patients. Schizophr Res. 2010;122(1-3):280-281.

14. Burt VK, Rudolph M. Treating an Orthodox Jewish woman with obsessive-compulsive disorder: maintaining reproductive and psychologic stability in the context of normative religious rituals. $\mathrm{Am} \mathrm{J}$ Psychiatry. 2000;157(4):620-624.

15. Reynolds CA, Raine A, Mellingen K, et al. Three-factor model of schizotypal personality: invariance across culture, gender, religious affiliation, family adversity, and psychopathology. Schizophr Bull. 2000;26(3):603-618

16. Fallon BA, Liebowitz MR, Hollander E, et al. The pharmacotherapy of moral or religious scrupulosity. J Clin Psychiatry. 1990;51(12):517-521. 
17. Cooper HM. The Integrated Research Review: a Systematic Approach Sage Publications, Beverly Hills, USA. 1984. p.143.

18. Kendler KS, Gardner CO, Prescott CA. Religion, psychopathology, and substance use and abuse; a multimeasure, genetic-epidemiologic study. Am J Psychiatry. 1997;154(3):322-329.

19. Miller L, Davies M, Greenwald S. Religiosity and substance use and abuse among adolescents in the National Comorbidity Survey. $J \mathrm{Am}$ Acad Child Adolesc Psychiatry. 2000;39(9):1190-1197.

20. Kendler KS, Liu XQ, Gardner CO, et al. Dimensions of religiosity and their relationship to lifetime psychiatric and substance use disorders. $\mathrm{Am}$ J Psychiatry. 2003;160(3):496-503.

21. Harden KP. Does religious involvement protect against early drinking? A behavior genetic approach. J Child Psychol Psychiatry. 2010;51(7):763-771.

22. Chi FW, Kaskutas LA, Sterling S, et al. Twelve-Step affiliation and 3-year substance use outcomes among adolescents: social support and religious service attendance as potential mediators. Addiction. 2009;104(6):927-939.

23. Francis LJ, Mullen K. Religiosity and attitudes towards drug use among 13-15 year olds in England. Addiction. 1993;88(5):665-672.

24. Ghandour LA, Karam EG, Maalouf WE. Lifetime alcohol use, abuse and dependence among university students in Lebanon: exploring the role of religiosity in different religious faiths. Addiction. 2009;104(6):940-948.

25. Mullen K, Williams R, Hunt K. Irish descent, religion, and alcohol and tobacco use. Addiction . 1996;91(2):243-254.

26. Blay SL, Batista AD, Andreoli SB, et al. The relationship between religiosity and tobacco, alcohol use, and depression in an elderly community population. Am J Geriatr Psychiatry. 2008;16(11):934-943.

27. Nimgaonkar VL, Fujiwara TM, Dutta M, et al. Low prevalence of psychoses among the Hutterites, an isolated religious community. Am J Psychiatry. 2000;157(7):1065-1070.

28. Mohr S, Brandt PY, Borras L, et al. Toward an integration of spirituality and religiousness into the psychosocial dimension of schizophrenia. Am J Psychiatry. 2006;163(11):1952-1959.

29. Linden SC, Harris M, Whitaker C, et al. Religion and psychosis: the effects of the Welsh religious revival in 1904-1905. Psychol Med. 2010;40(8):1317-1323.

30. Borras L, Mohr S, Brandt PY, et al. Religious beliefs in schizophrenia: their relevance for adherence to treatment. Schizophr Bull. 2007;33(5):1238-1246.

31. Moss Q, Fleck DE, Strakowski SM. The influence of religious affiliation on time to first treatment and hospitalization. Schizophr Res. 2006;84(2-3):421-426.

32. Cruz M, Pincus HA, Welsh DE, et al. The relationship between religious involvement and clinical status of patients with bipolar disorder. Bipolar Disord. 2010;12(1):68-76.

33. Mitchell L, Romans S. Spiritual beliefs in bipolar affective disorder: their relevance for illness management. J Affect Disord. 2003;75(3):247-257.

34. Pressman P, Lyons JS, Larson DB, et al. Religious belief, depression, and ambulation status in elderly women with broken hips. Am J Psychiatry. 1990;147(6):758-760

35. Koenig HG, Cohen HJ, Blazer DG, et al. Religious coping and depression among elderly, hospitalized medically ill men. Am J Psychiatry. 1992;149(12):1693-1700.

36. Koenig HG, George LK, Peterson BL. Religiosity and remission of depression in medically ill older patients. Am J Psychiatry. 1988;155(4):536-542.
37. Braam AW, Van den Eeden P, Prince MJ, et al. Religion as a crosscultural determinant of depression in elderly Europeans: results from the EURODEP collaboration. Psychol Med. 2001; 31(5):803-814.

38. King DA, Lyness JM, Duberstein PR, et al. Religious involvement and depressive symptoms in primary care elders. Psychol Med. 2007;37(12):1807-1815.

39. Braam AW, Beekman AT, Deeg DJ, et al. Religiosity as a protective or prognostic factor of depression in later life; results from a community survey in The Netherlands. Acta Psychiatr Scand. 1997;96(3):199-205.

40. Braam AW, Beekman AT, van den Eeden P, Et al. Religious climate and geographical distribution of depressive symptoms in older Dutch citizens. J Affect Disord. 1999;54(1-2):149-159.

41. Cruz M, Schulz R, Pincus HA, et al. The association of public and private religious involvement with severity of depression and hopelessness in older adults treated for major depression. Am J Geriatr Psychiatry. 2009; 17(6):503-507.

42. Koenig HG. Religion and depression in older medical inpatients. Am J Geriatr Psychiatry. 2007; 15(4):282-291.

43. Koenig HG, Hays JC, George LK, et al. Modeling the cross-sectional relationships between religion, physical health, social support, and depressive symptoms. Am J Geriatr Psychiatry. 1997;5(2):131-144.

44. Chatters LM, Bullard KM, Taylor RJ, et al. Religious participation and DSM-IV disorders among older African Americans: findings from the National Survey of American Life. Am J Geriatr Psychiatry. 2008;16(12):957-965.

45. Miller L, Warner V, Wickramaratne $\mathrm{P}$, et al. Religiosity and depression: ten-year follow-up of depressed mothers and offspring. J Am Acad Child Adolesc Psychiatry. 1997;36(10):1416-1425.

46. Miller L, Gur M. Religiosity, depression, and physical maturation in adolescent girls. $J$ Am Acad Child Adolesc Psychiatry. 2002;41(2):206-214.

47. Horowitz JL, Garber J. Relation of intelligence and religiosity to depressive disorders in offspring of depressed and nondepressed mothers. J Am Acad Child Adolesc Psychiatry. 2003;42(5):578-586.

48. Dew RE, Daniel SS, Goldston DB, et al. A prospective study of religion/ spirituality and depressive symptoms among adolescent psychiatric patients. J Affect Disord. 2010;120(1-3):149-157.

49. Azhar MZ, Varma SL. Religious psychotherapy in depressive patients. Psychother Psychosom. 1995;63(3-4):165-168.

50. Maselko J, Gilman SE, Buka S. Religious service attendance and spiritual well-being are differentially associated with risk of major depression. Psychol Med. 2009;39(6):1009-1017.

51. Nasser EH, Overholser JC. Recovery from major depression: the role of support from family, friends, and spiritual beliefs. Acta Psychiatr Scand. 2005;111(2):125-132.

52. Braam AW, Schrier AC, Tuinebreijer WC, et al. Religious coping and depression in multicultural Amsterdam: a comparison between native Dutch citizens and Turkish, Moroccan and Surinamese/Antillean migrants. J Affect Disord . 2010;125(1-3):269-278.

53. Neeleman J, Halpern D, Leon D, et al. Tolerance of suicide, religion and suicide rates: an ecological and individual study in 19 Western countries. Psychol Med. 1997;27(5):1165-1171.

54. Dervic K, Oquendo MA, Grunebaum MF, et al. Religious affiliation and suicide attempt. Am J Psychiatry. 2004;161(12):2303-2308.

55. Rasic DT, Belik SL, Elias B, et al. Spirituality, religion and suicidal behavior in a nationally representative sample. $J$ Affect Disord. 2009;114(1-3):32-40.

56. Azhar MZ, Varma SL, Dharap AS. Religious psychotherapy in anxiety disorder patients. Acta Psychiatr Scand. 1994;90(1):1-3. 
57. Kaplan Z, Matar MA, Kamin R, et al. Stress-related responses after 3 years of exposure to terror in Israel: are ideological-religious factors associated with resilience? J Clin Psychiatry. 2005; 66(9):1146-1154.

58. Azhar MZ, Varma SL. Religious psychotherapy as management of bereavement. Acta Psychiatr Scand. 1995;91(4):233-235.
59. Sanua VD. Religion, mental health, and personality: a review of empirical studies. Am J Psychiatry. 1969;125(9):1203-1213.

60. Koenig HG, King DE, Carson VB. Handbook of Religion and Health. (2nd edn), Oxford University Press, New York, USA. 2011. p. 1169 